\title{
Reassessment of the taxonomic position of Iranocypris typhlops Bruun \& Kaiser, 1944 (Actinopterygii, Cyprinidae)
}

\author{
Azita Farashi', Mohammad Kaboli', Hamid Reza Rezaei², \\ Mohammad Reza Naghavi ${ }^{3}$, Hassan Rahimian ${ }^{4}$, Brian W. Coad ${ }^{5}$
}

I Department of Environmental Sciences, Faculty of Natural Resources, University of Tehran, Iran 2 Department of Environmental Sciences, Faculty of Natural Resources, Gorgan University, Iran 3 Department of Agronomy and Plant Breeding, Faculty of Agricultural Sciences, University of Tehran, Iran 4 Department of Animal Biology, Faculty of Biology, University of Tehran, Iran 5 Canadian Museum of Nature, Ottawa, Ontario, Canada

Corresponding author: Mohammad Kaboli (mkaboli@ut.ac.ir)

Academic editor: K. Jordaens | Received 15 November 2013 | Accepted 9 January 2014 | Published 29 January 2014

Citation: Farashi A, Kaboli M, Rezaei HR, Naghavi MR, Rahimian H, Coad BW (2014) Reassessment of the taxonomic position of Iranocypris typhlops Bruun \& Kaiser, 1944 (Actinopterygii, Cyprinidae). ZooKeys 374: 69-77. doi: 10.3897/ zookeys.374.6617

\begin{abstract}
The Iranian cave barb (Iranocypris typhlops Bruun \& Kaiser, 1944) is a rare and endemic species of the family Cyprinidae known from a single locality in the Zagros Mountains, western Iran. This species is "Vulnerable" according to the IUCN Red List and is one of the top four threatened freshwater fish species in Iran. Yet, the taxonomic position of I. typhlops is uncertain. We examined phylogenetic relationships of this species with other species of the family Cyprinidae based on the mitochondrial cytochrome $b$ gene. Our results show that I. typhlops is monophyletic and is sister taxon of a cluster formed by Garra rufa (Heckel, 1843) and Garra barreimiae (Fowler \& Steinitz, 1956) within a clade that includes other species of the genus Garra. Based on previous molecular and morphological studies, as well as our new results, we recommend that I. typhlops should be transferred to the genus Garra Hamilton, 1822.
\end{abstract}

\section{Keywords}

Iranian cave barb, Iranocypris typhlops, Garra, phylogeny 


\section{Introduction}

The Iranian cave barb (Iranocypris typhlops Bruun \& Kaiser, 1944) is a rare and endemic species of the family Cyprinidae in the Zagros Mountains, western Iran (Mahjoorazad and Coad 2009). The distribution of the species seems to be restricted to a single cave. This species is currently recognized as "Vulnerable" according to the IUCN Red List (IUCN 2013). As such, Coad (2000) using 18 criteria that focused on distribution and habitat, found this species to be one of the top four threatened species of freshwater fishes in Iran. Zalaghi (2011) estimated the population size of the species between 353 and 625 individuals.

The species was suggested to be related to the genus Barbus Cuvier \& Cloquet, 1816 by Bruun and Kaiser (1944) but Saadati (1977) rejected the close relationship with the genus Barbus. Coad (2013) proposed that the species may be related to the genus Garra Hamilton, 1822. More recently, Hashemzadeh Segherloo et al. (2012) provided the first molecular evidence of the species phylogeny based on the cytochrome $c$ oxidase subunit I (COI) gene, which indicated that the species is phylogenetically close to the genus Garra. Two sympatric forms have been reported within I. typhlops (Sargeran et al. 2008). They are morphologically distinguished by the presence / absence of a mental disc on the ventral surface of the head (Fig. 1). The mental disc is the lower lip modified into a mental adhesive disc whose posterior margin is discontinuous with the mental region (Zhang 2005). Sargeran et al. (2008) and Hashemzadeh Segherloo et al. (2012) found morphological and molecular differentiations between the two sympatric forms, respectively. Also Hashemzadeh Segherloo et al. (2012) indicated that the two forms might represent separate species based on high intraspecific COI divergence between the two sympatric forms.

Phylogenetic studies of the cavefish populations have shown that some aspects of cavefish systematics are still debated and require molecular analyses to provide evidence on taxonomy and phylogenetic relationships. Detailed molecular studies on some cavefish species have actually shown that their taxonomic position needs a revision based on genetic evidence and that several species, whose description was based on morphological traits only, could be genetically closer to genera different from those to which they are currently assigned to (Romero and Paulson 2001, Colli et al. 2009). In this study, we used the mitochondrial cytochrome $b$ (cyt $b$ ) gene to examine the phylogenetic relationships of the species and in this way to assess the taxonomic position of I. typhlops.

\section{Study area}

The Iranian cave barb is found in a water cave, the natural outlet of a subterranean limestone system of the Zagros Mountains. The stream below the cave locality is the "Ab-e Serum" which is a tributary of the Dez River, in Lorestan province. The Dez flows into the Karun River, which drains to the head of the Persian Gulf. Further locality details are given in Bruun and Kaiser (1944) and Mahjoorazad and Coad (2009). The cave is located at $33^{\circ} 04^{\prime} 39^{\prime \prime} \mathrm{N}$ and $48^{\circ} 35^{\prime} 33^{\prime \prime} \mathrm{E}$ (Fig. 2). 

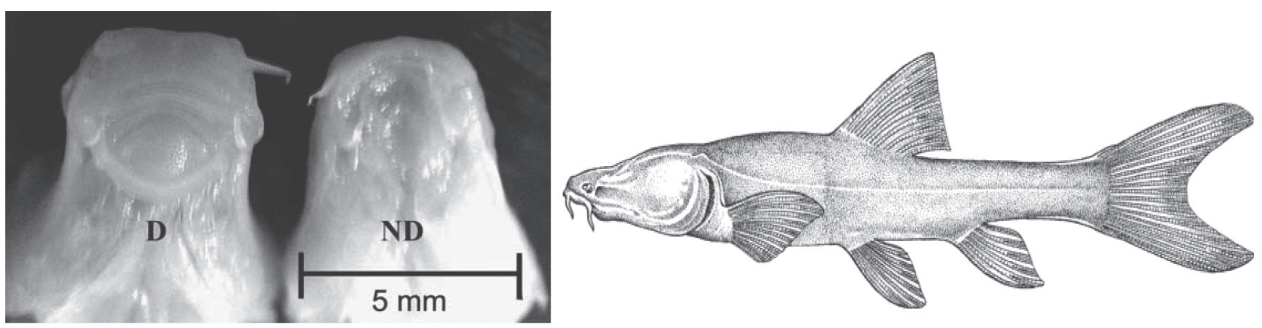

Figure I. (Left) Ventral view of heads of putative I. typhlops, with (D) and without (ND) a disc, adapted from Sargeran et al. (2008); (Right) I. typhlops, adapted from (Coad 2013).

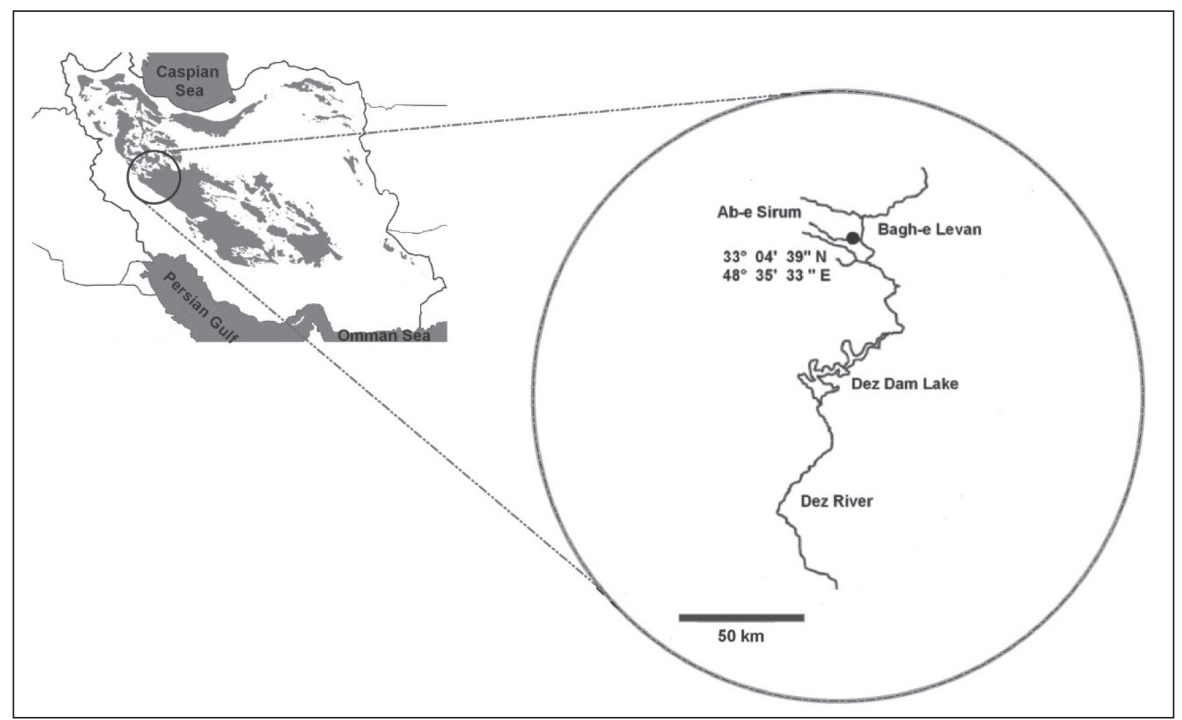

Figure 2. Location of I. typhlops habitat in Bagh-e Levan.

\section{Methods}

Fin-clip samples (approximately $4 \mathrm{~mm}^{2}$ ) of 16 I. typhlops specimens (eight specimens with a mental disc and eight specimens without a mental disc) were collected from the native habitat in November 2012. The fin-clips were stored in $98 \%$ ethanol. Total DNA was extracted using the DNeasy-Tissue Kit (Qiagen, Germany) following the manufacturer's instructions. PCR amplification cyt $b$ was performed using primers L15267 (R: 5'-AATGACTTGAAGAACCACCGT-3') and H16461 (F: 5'-CTTCGGATTACAAGACC-3') (Briolay et al. 1998). The Polymerase Chain Reaction (PCR) amplification reactions were carried out in $20 \mu \mathrm{l}$ reaction volume containing: $80 \mathrm{ng}$ of genomic DNA, 1.5 units of Taq polymerase, $1 \times$ Roche Taq PCR buffer, $2.5 \mathrm{mM}$ $\mathrm{MgCl}_{2}, 250 \mu \mathrm{M} d \mathrm{dTPs}$ and $0.25 \mathrm{pM}$ of each primer. PCR reactions were conducted under the following conditions: 5 min denaturation at $94{ }^{\circ} \mathrm{C} ; 30$ cycles of $40 \mathrm{~s}$ at 94 ${ }^{\circ} \mathrm{C}, 35 \mathrm{~s}$ at $50^{\circ} \mathrm{C}$ and $30 \mathrm{~s}$ at $72^{\circ} \mathrm{C}$ and a final extension at $72{ }^{\circ} \mathrm{C}$ for $5 \mathrm{~min}$. PCR products were sequenced on an ABI-3130xl sequencer using the manufacturer's protocol. 
Sequences were aligned using ClustalX (Thompson et al. 1997) and manually checked for inconsistencies. The sequences were deposited in GenBank under accession numbers KF896290 to KF896300. Number of haplotypes, analysis of molecular variance (AMOVA) among and within the two sympatric forms (with and without mental disc), and Kimura two-parameter (K2P) distances (Kimura 1980), were calculated using ARLEQUIN 3.5.1.3 (Excoffier and Lischer 2010).

For the reconstruction of phylogenetic trees, cyt $b$ sequences of different cyprinid species (Fig. 3) were retrieved from GenBank and aligned with the sequences of I. typhlops. Myxocyprinus asiaticus (Gill, 1878) was included as outgroup (Hashemzadeh Segherloo et al. 2012). Maximum likelihood (ML), neighbor-joining (NJ) and Bayesian analysis (BI) were used to infer phylogenetic trees. The Akaike Information Criterion, the corrected AIC and the Bayesian Information Criterion in jModeltest 2.1.3 (Posada 2008) were used to select an appropriate substitution model of DNA evolution. The GTR model of evolution with gamma shape parameter $(\mathrm{G}=1.24)$ and proportion of invariable positions $(\mathrm{I}=0.54)$ was the selected model according to the three criteria. ML analysis was conducted using PAUP 4.0b10 (Swofford 2003). ML tree searches were performed by heuristic searches. NJ analysis, based on K2P distances, was derived using "dnadist" and "neighbor" executables implemented in Phylip 3.6 (Felsenstein 2005). Support for nodes was assessed by nonparametric bootstrapping (1000 replicates) for ML and NJ analysis and only values $>50 \%$ were considered (Colli et al. 2009, Tang et al. 2009). Bayesian analysis was carried out using MrBayes 3.1.2 (Ronquist and Huelsenbeck 2003). The Markov Chain MonteCarlo (MCMC) search was run for $10^{6}$ generations, sampling the Markov chain every 100 generations. The first 25\% (1000) trees were discarded as burn-in.

\section{Results}

After trimming the alignment, the cyt $b$ gene sequences were 904 bp long and 11 haplotypes were found for the 16 sequenced samples (four haplotypes for specimens with mental disc and seven haplotypes for specimens without mental disc). AMOVA showed that $95.72 \%$ of the variation in cyt $b$ sequences was attributed to differences among the two sympatric forms (Table 1). Also FST value showed significant genetic variation among the two sympatric forms. ML, NJ and BI analyses yielded phylogenetic trees with almost the same topology but the consensus tree of BI supported the relationships among species with higher posterior probabilities (Fig. 3). Genetic divergences among I. typhlops and 22 species of the family Cyprinidae are presented in Table 2.

\section{Discussion}

The phylogenetic trees showed that both forms of I. typhlops form a single clade and that this clade is a sister group of a clade comprising Garra rufa (Heckel, 1843) and Garra barreimiae (Fowler \& Steinitz, 1956). These two sister clades are placed within 
Table I. Analysis of AMOVA among the two sympatric forms of I. typhlops.

\begin{tabular}{l|l|l|l|l}
\hline Source of variation & d.f. & Sum of squares & Variance components & Percentage variation \\
\hline Among sympatric forms & 1 & 143.318 & 17.815 & 95.720 \\
\hline Within sympatric forms & 14 & 11.160 & 0.7971 & 4.280 \\
\hline Total & 15 & 154.478 & 18.612 & 100.000 \\
\hline
\end{tabular}

$\mathrm{F}_{\mathrm{ST}}=0.957(\mathrm{P}$-value $=0.0000)$

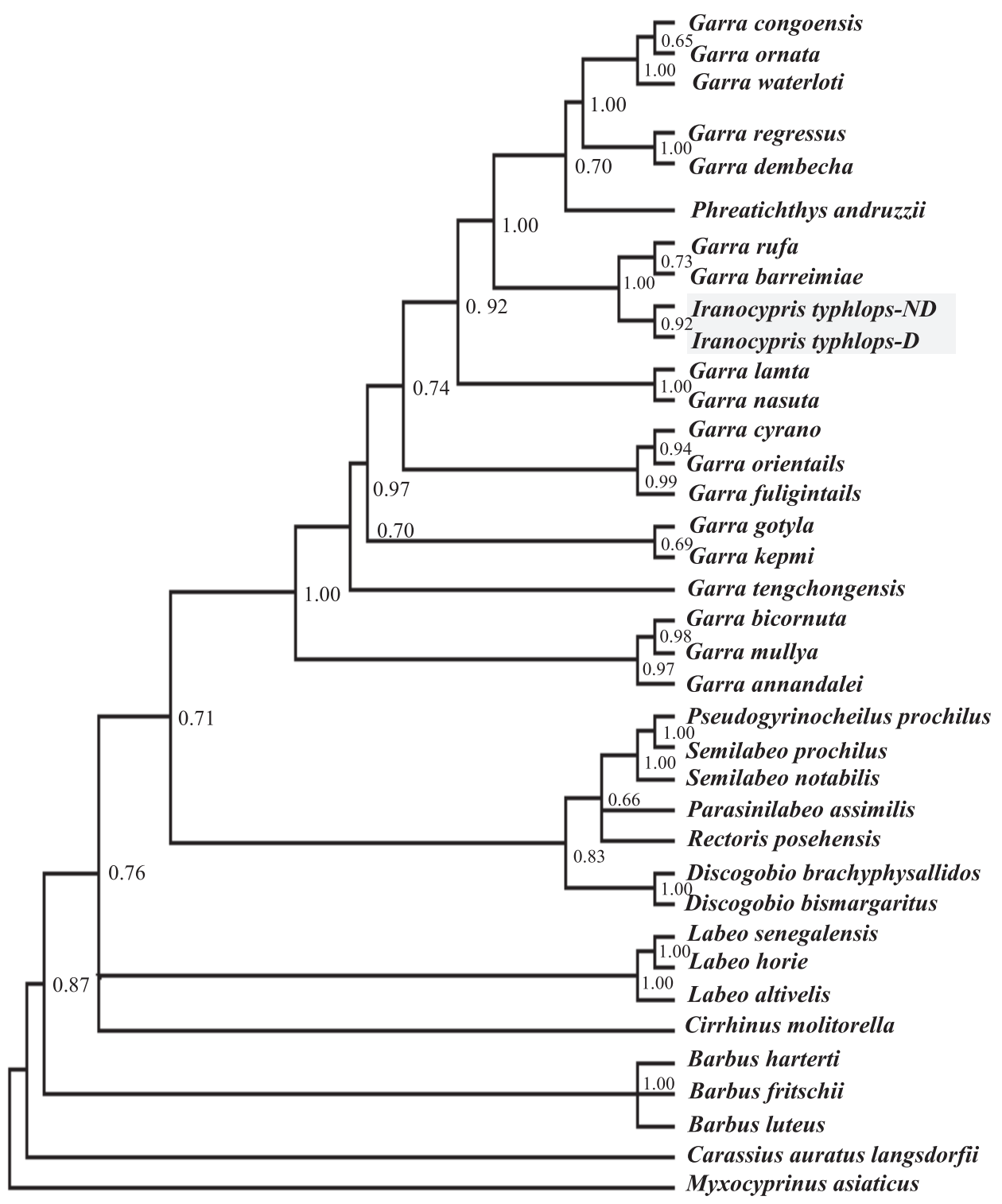

Figure 3. Phylogenetic relationships of $I$. typhlops based on cyt $b$. The posterior probability values on the branches are the results of BI. I. typhlops- $N D=$ specimens without a mental disc, I. typhlops- $D=$ specimens with a mental disc. 


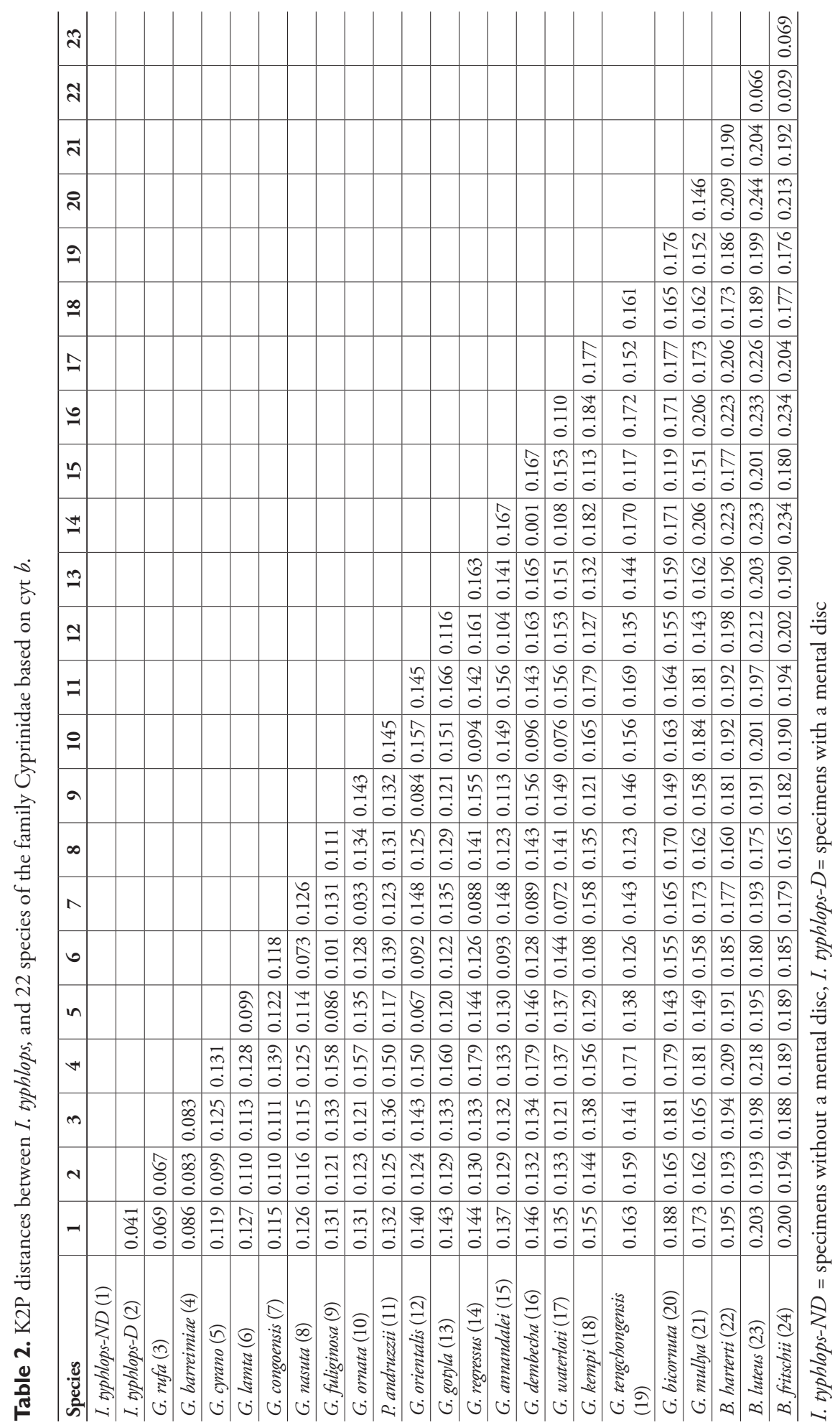


a large clade that includes the other species of the genus Garra, as well as Phreatichthys andruzzii (Vinciguerra, 1924). Colli et al. (2009) also surveyed the phylogeny of $P$. andruzzii and $G$. barreimiae with cyt $b$ and reported similar results. Therefore, these authors suggested that the taxonomic position of $P$. andruzzii should be revised, while earlier Banister (1984) had already reported that based on osteological data the genus Phreatichthys is closely related to Garra.

Bruun and Kaiser (1944) reported that I. typhlops is similar to the genus Barbus. Yet, according to the K2P distances between I. typhlops and species of the genera Garra and Barbus (Table 2), and the resulting phylogenetic trees, the species is most closely related to the genus Garra and only distantly related to the genus Barbus. Saadati (1977) rejected a relationship between I. typhlops and Barbus species from the Tigris River basin because of their large size differences and lack of a mental disc. Finally, our results are also similar to those of Hashemzadeh Segherloo et al. (2012), who assessed the phylogenetic position of $I$. typhlops using the mitochondrial COI gene.

We observed a mean K2P divergence of $4.1 \%$ between the two forms of $I$. typhlops. The intraspecific divergence is higher than the mean K2P divergence reported among other fishes, e.g. $0.78 \%$ for marine fishes (Zhang and Hanner 2012) and 1.1 $\%$ for freshwater fishes (Hedrick et al. 2006). Hashemzadeh Segherloo et al. (2012) also reported a similar divergence between both forms at COI. The high genetic distances between the two sympatric forms of I. typhlops, along with the morphological differences between the two sympatric forms of I. typhlops (Sargeran et al. 2008), may be due to particularities inherent to evolutionary processes in subterranean habitats (Hashemzadeh Segherloo et al. 2012).

The mental disc is the key character of species of the subfamily Labeoninae including Iranocypris and Garra. The genus Garra is similar to the genus Iranocypris in having three rows of pharyngeal teeth (Abbasi and Gharzi 2008, Coad 2013). Conversely, Bruun and Kaiser (1944) described I. typhlops as a new genus and a new species based on its two rows of pharyngeal teeth. Coad (2013) reported one to three teeth in the outer row, three to four teeth in the middle row and three to five teeth in the inner row. This condition, however, is also found in the genus Garra (typically 2, 4, 5-5, 4, 2 teeth in each row, respectively). Earlier, Sargeran et al. (2008) investigated morphometric and meristic features of $I$. typhlops to conclude that this species is similar to species of the genus Garra. Finally, we recommend that I. typhlops is transferred to the genus Garra and Iranocypris Bruun \& Kaiser, 1944 is to be regarded as a species of Garra Hamilton, 1822.

\section{Acknowledgements}

The publication of this paper was made possible through funding and support from the EC project ViBRANT (Virtual Biodiversity Research and Access Network for Taxonomy) and the Belgian FWO research community project "Belgian Network for DNA Barcoding" (BeBoL). 


\section{Reference}

Abbasi M, Gharzi A (2008) Morphology and histology of the digestive tract of Iranian blind cave fish (Iranocypris typhlops). Iranian Veterinary Journal 4: 60-69.

Banister KE (1984) A subterranean population of Garra barriemiae (Teleostei: Cyprinidae) from Oman, with comments on the concept of regressive evolution. Natural History 18: 927-938.

Banister KE, Bunni MK (1980) A new blind cyprinid fish from Iraq. Bulletin of the British Museum (Natural History) Zoology 38: 151-158.

Briolay J, Galtier N, Brito RM, Bouvet Y (1998) Molecular phylogeny of Cyprinidae inferred from cytochrome $b$ DNA sequences. Molecular Phylogenetics and Evolution 9: 100-108. doi: 10.1006/mpev.1997.0441

Bruun AF, Kaiser EW (1944) Iranocypris typhlops n.g., n.sp., the first true cave fish from Asia. Danish Scientific Investigations in Iran, Copenhagen 4: 1-8.

Coad BW (2000) Criteria for assessing the conservation status of taxa (as applied to Iranian freshwater fishes). Biologia 55: 539-557.

Coad BW (2013) Freshwater fishes of Iran. http://www.briancoad.com/Contents.htm [accessed 03 November 2013]

Colli L, Paglianti A, Berti R, Gandolfi G, Tagliavini J (2009) Molecular phylogeny of the blind cavefish hreatichthys andruzzii and Garra barreimiae within the family Cyprinidae. Environmental Biology of Fishes 84: 95-107. doi: 10.1007/s10641-008-9393-z

Excoffier L, Lischer HE (2010) Arlequin suite, version 3.5: a new series of programs to perform population genetics analyses under Linux and Windows. Molecular Ecology Resources 10: 564-567. doi: 10.1111/j.1755-0998.2010.02847.x

Felsenstein J (2005) PHYLIP (Phylogeny Inference Package) Version 3.6. Distributed by the author. Department of Genome Sciences, University of Washington, Seattle.

Hashemzadeh Segherloo I, Bernatchez L, Golzarianpour K, Abdoli A, Primmer CR, Bakhtiary M (2012) Genetic differentiation between two sympatric morphs of the blind Iran cave barb Iranocypris typhlops. Journal of Fish Biology 81: 1747-53. doi: 10.1111/j.10958649.2012.03389.x

Hedrick PW, Lee RN, Hurt C (2006) The endangered Sonoran topminnow: Examination of species and ESUs using three mtDNA genes. Conservation Genetics 7: 483-492. doi: $10.1007 / \mathrm{s} 10592-005-9058-9$

IUCN (2013) IUCN Red List of Threatened Species, Version 2013.1. www.iucnredlist.org [accessed 03 November 2013]

Kimura M (1980) A simple method for estimating evolutionary rate of base substitutions through comparative studies of nucleotide sequences. Journal of Molecular Evolution 16: 111-120. doi: 10.1007/BF01731581

Mahjoorazad A, Coad BW (2009) A new cave fish locality for Iran. Electronic Journal of Ichthyology 2: 30-33.

Posada D (2008) jModelTest: phylogenetic model averaging. Molecular Biology and Evolution 25: 1253-1256. doi: 10.1093/molbev/msn083

Romero A (2001) Scientists prefer them blind: the history of hypogean fishes research. Environmental Biology of Fishes 62: 43-7. doi: 10.1023/A:1011830329016

Romero A, Paulson KM (2001) It's a wonderful hypogean life: a guide to the troglomorphic fishes of the world. Environmental Biology of Fishes 62: 13-41. doi: 10.1023/A:1011844404235 
Ronquist F, Huelsenbeck JP (2003) MrBayes 3: Bayesian phylogenetic inference under mixed models. Bioinformatics 19: 1572-1574. doi: 10.1093/bioinformatics/btg180

Saadati MAG (1977) Taxonomy and distribution of the freshwater fishes of Iran. MS Thesis, Colorado State University, Fort Collins, U.S.A.

Sargeran P, Bakhtiyari M, Abdoli A, Coad BW, Sarvi K, Rahmati Lishi M, Hajimoradloo A (2008) The endemic Iranian cave-fish, Iranocypris typhlops: two taxa or two forms based on the mental disc? Journal of Zoology in the Middle East 44: 67-74. doi: 10.1080/09397140. 2008.10638290

Swofford DL (2003) PAUP*: Phylogenetic analysis using parsimony (* and Other Methods). Version 4.0b10. Sinauer Associates, Sunderland, Massachusetts.

Tang Q, Getahun A, Liu H (2009) Multiple in-to-Africa dispersals of labeonin fishes (Teleostei: Cyprinidae) revealed by molecular phylogenetic analysis. Hydrobiologia 632: 261-271. doi: $10.1007 / \mathrm{s} 10750-009-9848-\mathrm{z}$

Thompson JD, Gibson TJ, Plewniak F, Jeanmougin F, Higgins DG (1997) The Clustal X windows interface: flexible strategies for multiple sequences alignment aided by quality analysis tools. Nucleic Acids Research 25: 4876-4882. doi: 10.1093/nar/25.24.4876

Zalaghi A (2011) Study of habitat and population of the Iranian Cave-fish. Ms thesis, Islamic Azad University, Tehran, 101 pp.

Zhang E (2005) Phylogenetic relationships of labeonine cyprinids of the disc-bearing group (Pisces: Teleostei). Zoological Studies 44: 130-143.

Zhang J, Hanner R (2012) Molecular Approach to the Identification of Fish in the South China Sea. PLoS ONE 7: e30621. doi: 10.1371/journal.pone.0014156 